\title{
Analysis on the Business Strategy of Tesco in the Chinese Market
}

\author{
Qi Tian \\ Shanghai University of Electric Power, Shanghai 200090, China (Graduated from Newcastle University) \\ Email: tianqi64@126.com
}

\begin{abstract}
As China's joining World Trade Organization (WTO) and entirely opening its retail market, foreign retailers step into China one after the other. The Chinese retailing industry has changed rapidly influenced by both external and internal factors. Tesco, the great retail chain in the UK, transferred its value to the Chinese market in 2004. Tesco has implemented various strategy since it launched in China. The British retail giant has experienced tremendous success in the British retail market. However, it is struggling to succeed after nine years of solo venture in the Chinese market.
\end{abstract}

Keywords: China's retail market, consumer behaviour, Tesco's strategy

\section{Introduction}

With China's accession to the WTO in 2001, the government has opened up retail markets continually. All foreign retailers were given greater freedom and chance to engage in the retail sector in the Chinese market. The immediate benefit of the policies of expansion rules and China's increasing openness to the foreign companies was the rapid emergence of consumption power, for an increasing range of innovative products from name brand foreign retailers. It seems China was the best choice for foreign retailers to invest and launch store at that time. In 2004, Tesco entered the Chinese market with "go it alone" entry strategy. The vast scale of the country and the cultural differences between China's various regions make Tesco more appropriate to view the state as a collection of markets.

With the Chinese dream, Tesco transfers its core value to China. Due to the rapid changes in China's retail market and consumer behaviour, some of the earlier research of Tesco provides inaccurate background information on the real China's retail industry. After nine years, Tesco negotiations with China's biggest retailer to create a new joint venture. As a result of it, Tesco hold only $20 \%$ stake. However, $80 \%$ stake belongs to the state-owned company, China Resources Enterprise. It means the Tesco brand is likely to disappear from the Chinese market.

\section{Related literature}

Firstly, Tesco set up segments for different levels of customers to choose. As for the profit factor, the retailers also should be concerned about after-sales services of all different classes to make sure the quality of services. However, Tesco needs a particular business plan to achieve the goals when it faces the unique market. Unfortunately, these key factors were not grasped by Tesco. On the contrary, Tesco may blindly follow strategies enacted by its competitors or copy the mode of its past sales models without analyzing the current situations of the Chinese market. Tesco only sees the potential of consumption power and no longer takes the satisfaction degree of the consumers into consideration.

Secondly, the "secret weapon" didn't gain any success due to the different consumer behaviour in China. The Chinese customers like something for free or discount better. Comparing to other foreign companies in China like IKEA, Tesco didn't fully understand the power of culture. IKEA offers shoppers a free cup of tea or coffee, and a piece of newspaper or magazine to all the loyalty card holder. That is what the customers need and want in the Chinese market. They do not wish to save points owing it is meaningless and full of gimmicks. The Chinese customers usually take a long time to make the purchase decision because they want to see the card value every time they shop at Tesco. If not, they could change their choice of supermarket.

Thirdly, Tesco needs a business plan for each stage. The first plan is related to entry strategy. Since regulations changed, China has allowed companies develop their business alone. However, if it is the first time that for foreign companies enter China, the joint venture seems the best choice. Based on the case study, many firms choose joint venture or strategic alliance as the way to enter the Chinese market such as KFC, Domino's Pizza, and Nestle. However, Tesco selects "go it alone" strategy. It lost the opportunities of building local scale quicker and acquiring local knowledge. To review the Chinese market, one foreign company was hard to gain success without the help of a local partner. As for KFC, it is a very successful foreign corporation in China that gives the strong evidence of the power of co-work with local 
firms (Bell, 2011). Nestle, the Swiss food giant, also gets the help from partners to create different flavours to cater to the Chinese local tastes in all their products.

It is obvious that Tesco implements some crucial strategies in China. Still, these strategies play no roles in markets. Tesco transferred its perfect UK model to the Chinese market without changing the organization structure and management methods (Roth, 2009). This successful model may not run very well on other sites. Moreover, customer characteristics, consumer behaviour, accessibility, competition with local or foreign retailers, prestige and cost budget have been found to be the crucial factors in setting up a new strategic plan.

\section{Strategy}

The researcher will evaluate each strategy that Tesco implemented in China.

\subsection{Joint venture strategy}

From the research, many companies choose joint ventures (JVs) as the preferred choice when they entered a new market. In Tesco's history, the most successful one in Asia is Tesco Lotus, which is between Tesco PLC and CP Group of Thailand. However, it was extremely foolhardy to launch a business without JVs with a Chinese partner. In the Chinese market, the key to becoming an outstanding retailer is related to suppliers, consumers, and government (Teo Kermeliotis, 2011). Without the help of experience and knowledge from a local retailer, Tesco can hardly achieve success.

\subsection{Expansion strategy}

In China, from the research that other retailers have already did, Tesco can share secondary data to analyze the value of each region. Those geographically close regions share the similar cultures and social issues. It will help retailers to expand in large-scale markets in one single country. Cultural distance was also linked to psychic distance and business distance. From Tesco's expansion strategy, the distance between the home market and the Chinese market results from the perception and understanding of cultures as well as business differences.

The Chinese market was no longer limited to first-tier cities. In this regard, Tesco changes the strategy. The leadership structure and innovative ideas may play the significant roles in retail expansion strategy. Tesco wants to remain competitive, and it should ensure that the current approach to market covers more than just bigger cities in case losing touch with consumers and becoming marginal players.

\subsection{Multichannel strategy}

Back to the 60s, supermarkets started to expand rapidly by selling more kinds of products in ever larger stores than before, so there is a trend of retail corporations goes the way of multichannel (Kwon, 2009). Tesco's multichannel strategy includes clothing, petrol, real estate, and other non-food lines in China. However, Tesco seems not to fit the Chinese demands on other aspects mainly because of the strategic choice and cultural differences.

\subsection{Promotion and advertising strategy}

All kinds of advertisement are growing impressively in popularity. There is a close relationship between publicity and brand loyalty. A frequent advertising with the objective of increasing mental association enhanced purchase power within the brand image. With regards to Tesco's advertising strategy, they should increase the proportion of new media, for instant, Weibo, cinema, Weixin, and public transit. Tesco focuses on a more traditional way of promotion while ignoring the trends of new media power in the past. Though new media have not yet totally replaced traditional media, it has a great potential for foreign retailers to promote their products and services (Wolf, 2015). The aim of new media advertising is to reach and appeal to new consumers in lower-tier cities, which are set to expand faster than more developed areas.

\subsection{Communication and public relation strategy}

The communication activities of the company are entirely influenced by the cultural issues such as market research, mass promotion, segmentation, and targeting. Tesco did less on corporate communications to build an effective public relation in China. After Tesco had entered, events surrounding the 2008 Beijing Olympics and the earthquake in Sichuan provided a platform where communication strategies took unexpected turns. However, Tesco did not grasp the opportunity to improve corporate social responsibility. As global name brand retail chain, Tesco should participate more to win the reputation within nationwide. The corporate social responsibility always plays a role in maintaining the corporation's reputation in the Chinese market.

\subsection{Clubcard strategy}

The loyalty card with a database behind it can provide Tesco with an unprecedented level of data details. These 
information including shopper's characteristics, just like a personal assistant to list all the goods that customers prefer to buy. Then, use coupon and voucher to return to the consumer as a gift for their loyalty. Without loyalty programs, a customer can easily to switch to other brands by their preferable products and services. From peer interaction point of view, Tesco needs to restructure how to add value to its brand and gain a higher level of brand awareness.

For instance, if the customers spend hundreds one time, they would like to save points because it is worth. If not, they may think it is unnecessary to use Clubcard for collecting points. For the promiscuous consumers, the value of points built up at one retailer is diminished. That is the main reason that Clubcard no longer keeps its business value caused by consumer behaviour change. In other words, customers are unwilling to save points for tomorrow, they prefer the direct discount today.

\subsection{Localization strategy}

Localization strategy includes many aspects such as products, human resource management, quality inspection and quarantine. It is helpful to get in touch with zone committee and administration, and improve local government affairs (Chaney, 2008). From research, most consumers considered that Tesco's products cannot satisfy their needs. In some extent, culture becomes the barrier of cross-country business. Likewise, it also can be the target of business. Tesco should focus on changing elements of the marketing mix to make the products or service better suited to customers' needs and want in the Chinese market.

\subsection{Pricing strategy}

The pricing strategy seems the most complicated problem for each retailer, especially in China. Grewal et al. (2011) examined the diverse consumption power and price sensitive rate, retailers should be assigned prices offering vary in different regions. The advantage of low price one can reflect on increasing sale quickly. Behind low price, there exist a complex mechanism to maintain the profit. There are some key factors that influenced pricing process, which are market reference price, incentive, and promotion activities. Although Tesco provides low price products, it neglects the quality of them.

\subsection{Location strategy}

The market location selecting has been identified as the most important factor in the retail industry. Beyond the location, retailers should consider political, economic, social matters and cultural issues. Purchase power of each region as well as the model of business will use. Foreign retailers claim that they can get suggestions from a local partner. The convenient location provides high potential for future success. Therefore, each strategy has a strong link each other for business chain reactions. In recent years, with the support of government, urbanization will continue to be the guide of the development of retailing. Moreover, Tesco should focus on small cities or towns to gain the further market share. The location also needs rethink since the booming of urbanization.

\subsection{E-commercial strategy}

With e-commerce expanding strongly, clients are more eager for high-technology and efficient life. The Internet and online shopping has truly transformed the pattern of consumption. From research analysis, the online shopping becomes paramount for success in this increasingly demanding market (GO-Globe, 2013). On the contrary, Tesco pays less attention to the development of e-business in China.

\subsection{Self-development strategy}

The company's own-label products are on sale at three levels in Tesco's home market, value, normal, and finest. However, in China, the own-label products do not enjoy any advantages comparing to other brand products due to poor quality and uselessness. These own-label products should focus on what customers need, not just for sale. Moreover, on a strategic level, Tesco neglected brand positioning strategy. Clearly, what works in Britain will probably not work in China. Far from retreating in China, Tesco should regroup, reposition and rebrand with "exclusivity" as core brand value.

\section{Conclusion}

All these strategies aim to resolve three main problems. Firstly, an adaptation to the external and internal environment. It means Tesco should know the "game rules" as regulations and limitations in China. Beyond all doubts, Tesco must cater to Chinese consumers from goods to services with passion and ambition. Secondly, Tesco must response to psychic distance and cultural patterns. It highlights the core value beyond the transfer of Tesco spirit. Through localization and JVs with a local partner, understand the consumer behaviour behind culture, combine them in a flexible way to ensure the quality of 
strategy plan. Thirdly, develop a comprehensive China strategy. A flexible business plan, appropriate management method, an efficient social networking system, all these are essential for Tesco. In a word, strategy and management can influence retailer performance in the Chinese market.

In summary, Tesco has gone through many hard lessons including poor management methods, wrong strategic choices, inflexible business plans, misunderstanding the culture issues and consumer behaviour, mismatching products and services offerings. To sum up, as a name brand retail giant, Tesco shows few advantages in the Chinese market.

\section{References}

[1] Bell D, Shelman M. KFC's Radical Approach to China. Harvard Business Review. 2011; 89(11): 137-142. Available from: https://hbr.org/2011/11/kfcs-radical-approach-to-china.

[2] Chaney I, Gamble J. Retail store ownership influences on Chinese consumers. International Business Review. 2008; 17(2): 170-183.

[3] GO-Globe. (2013) E-commerce In China - Statistics and Trends [Infographic].

[4] Grewal, D., Ailawadi, K., Gauri, D., Hall, K., Kopalle, P., Robertson, J. Innovations in Retail Pricing and Promotions. Journal of Retailing. 2011; 87: S43-S52.

[5] Grewal, D., Levy, M. Retailing research: Past, present, and future. Journal of Retailing. 2007; 83(4): 447-464.

[6] Kwon, W., Lennon, S. Reciprocal Effects Between Multichannel Retailers Offline and Online Brand Images. Journal of Retailing. 2009; 85(3): 376-390.

[7] Roth, K., Diamantopoulos, A. Advancing the country image construct. Journal of Business Research. 2009; 62(7): 726-740.

[8] Teo Kermeliotis, F. (2011) Doing business in China: Five tips for success - CNN.com.

[9] Wolf, N. (2015) 3 reasons why your marketing plans should include WeChat. 